\title{
The fate of cranial neuropathy after flow diversion for carotid aneurysms
}

\author{
Benjamin L. Brown, MD, ${ }^{1}$ Demetrius Lopes, MD, ${ }^{2}$ David A. Miller, MD, ${ }^{1}$ Rabih G. Tawk, MD, ${ }^{1}$ \\ Leonardo B. C. Brasiliense, MD, ${ }^{1}$ Andrew Ringer, MD, ${ }^{3}$ Eric Sauvageau, MD, ${ }^{4}$ \\ Ciarán J. Powers, MD, PhD, ${ }^{5}$ Adam Arthur, MD, ${ }^{6}$ Daniel Hoit, MD, ${ }^{6}$ Kenneth Snyder, MD, PhD, ${ }^{7}$ \\ Adnan Siddiqui, MD, PhD, ${ }^{7}$ Elad Levy, MD, ${ }^{7}$ L. Nelson Hopkins, MD, ${ }^{7}$ Hugo Cuellar, MD, ${ }^{8}$ \\ Rafael Rodriguez-Mercado, MD, ${ }^{9}$ Erol Veznedaroglu, MD, ${ }^{10}$ Mandy Binning, MD, ${ }^{10} \mathrm{~J}$ Mocco, MD, ${ }^{11}$ \\ Pedro Aguilar-Salinas, MD, ${ }^{12}$ Alan Boulos, MD, ${ }^{13}$ Junichi Yamamoto, MD, PhD, ${ }^{13}$ and \\ Ricardo A. Hanel, MD, PhD ${ }^{4}$
}

1Department of Neurosurgery, Mayo Clinic, Jacksonville, Florida; '2Department of Neurosurgery, Rush University Medical Center, Chicago, Illinois; '3Department of Neurosurgery, University of Cincinnati, Ohio; ${ }^{4}$ Lyerly Neurosurgery, Baptist Health, Jacksonville, Florida; ${ }^{5}$ Department of Neurological Surgery, The Ohio State University, Columbus, Ohio; ${ }^{6}$ Semmes Murphey Neurologic and Spine Institute, Semmes Murphey Clinic, Memphis, Tennessee; 'Department of Neurosurgery, University of Buffalo, New York; ${ }^{8}$ Department of Neurosurgery, Louisiana State University, Shreveport, Louisiana; ${ }^{9}$ Department of Neurosurgery, University of Puerto Rico Medical Sciences, San Juan, Puerto Rico; ${ }^{10} \mathrm{Capital}$ Institute for Neurosciences, Capital Health, Trenton, New Jersey; ${ }^{11}$ Department of Neurological Surgery, Vanderbilt University, Nashville, Tennessee; ${ }^{12}$ National Institute of Medical Sciences and Nutrition, Salvador Zubiran, Mexico City, Mexico; and ${ }^{13}$ Department of Neurosurgery, Albany Medical Center, Albany, New York

OBJECTIVE The authors sought to determine whether flow diversion with the Pipeline Embolization Device (PED) can approximate microsurgical decompression in restoring function after cranial neuropathy following carotid artery aneurysms.

METHODS This multiinstitutional retrospective study involved 45 patients treated with PED across the United States. All patients included presented between November 2009 and October 2013 with cranial neuropathy (cranial nerves [CNs] II, III, IV, and VI) due to intracranial aneurysm. Outcome analysis included clinical and procedural variables at the time of treatment as well as at the latest clinical and radiographic follow-up.

RESULTS Twenty-six aneurysms (57.8\%) were located in the cavernous segment, while $6(13.3 \%)$ were in the clinoid segment, and $13(28.9 \%)$ were in the ophthalmic segment of the internal carotid artery. The average aneurysm size was $18.6 \mathrm{~mm}$ (range 4-35 mm), and the average number of flow diverters placed per patient was 1.2. Thirty-eight patients had available information regarding duration of cranial neuropathy prior to treatment. Eleven patients $(28.9 \%)$ were treated within 1 month of symptom onset, while $27(71.1 \%)$ were treated after 1 month of symptoms. The overall rate of cranial neuropathy improvement for all patients was $66.7 \%$. The $\mathrm{CN}$ deficits resolved in 19 patients (42.2\%), improved in $11(24.4 \%)$, were unchanged in $14(31.1 \%)$, and worsened in $1(2.2 \%)$. Over time, the rate of cranial neuropathy improvement was $33.3 \%(15 / 45), 68.8 \%(22 / 32)$, and $81.0 \%$ (17/21) at less than 6, 6, and 12 months, respectively. At last follow-up, $60 \%$ of patients in the isolated CN II group had improvement, while in the CN III, IV, or VI group, $85.7 \%$ had improved. Moreover, 100\% (11/11) of patients experienced improvement if they were treated within 1 month of symptom onset, whereas $44.4 \%$ (12/27) experienced improvement if they treated after 1 month of symptom onset; $70.4 \%$ (19/27) of those with partial deficits improved compared with $30 \%$ (3/10) of those with complete deficits.

CONCLUSIONS Cranial neuropathy caused by cerebral aneurysm responds similarly when the aneurysm is treated with the PED compared with open surgery and coil embolization. Lower morbidity and higher occlusion rates obtained with the PED may suggest it as treatment of choice for some of these lesions. Time to treatment is an important consideration regardless of treatment modality.

http://thejns.org/doi/abs/10.3171/2015.4.JNS142790

KEY WORDS aneurysm; cranial neuropathy; flow diversion; Pipeline Embolization Device; vascular disorders 
$\mathrm{M}$ ICROSURGERY remains the gold standard for decompression of cranial nerves (CNs) affected by aneurysmal mass effect. Over the past 2 decades, coil embolization has gained rapid acceptance as a viable alternative. For the treatment of large unruptured aneurysms of the proximal internal carotid artery, flow diversion has grown in popularity as an alternative to both microsurgery and coil embolization. Cranial nerve compression is not an uncommon presenting symptom for these aneurysms. For cavernous aneurysms, the presenting symptom is diplopia in about $65 \%$ of patients, while decreased visual acuity affects approximately $16 \%$ of patients. ${ }^{30}$

The question of whether endovascular flow diversion can approximate microsurgical decompression in restoring function in cranial neuropathy remains unanswered. To our knowledge, there have been no studies focusing on the results of cranial neuropathy after Pipeline Embolization Device (PED; Covidien) flow diversion. We set out to review this subject in the following multiinstitutional study.

\section{Methods}

This study was approved by each participating institution's review board. The medical records of patients presenting with cranial neuropathy (CNs II, III, IV, and VI) due to cerebral aneurysm treated with flow diversion between November 2009 and October 2013 were retrospectively reviewed. Ten institutions from North America, led by the Endovascular Neurosurgery Research Group, contributed patient data. Antiplatelet agents were used for all patients in the pre- and postoperative period; however, the antiplatelet agent and dosage varied per each institution's standard. All outcomes were assessed during routine office visits and were based on the clinical judgment of each physician at the treating institutions. All patients were treated using the PED. The PED was sized according to standard protocol to be larger than the maximum diameter of the target vessel to ensure good wall apposition. Additional devices were deployed at the surgeon's discretion to increase stasis within the aneurysm or to ensure complete coverage of a lesion if a longer construct was required.

Patient demographics, presentation deficit, duration of deficit prior to treatment, aneurysm demographics, number of flow diverters used, presence/absence of coils, cranial neuropathy outcome (resolved, improved, unchanged, or worse), clinical complications, and radiographic outcome (Raymond classification ${ }^{28}$ ) were recorded. Subanalyses were performed for CN II and CNs III, IV, and VI. Cranial nerves III, IV, and VI were grouped together because of their similar function. Some patients involved in the study were also reported on in the Pipeline for Uncoilable or Failed Aneurysms Study. ${ }^{2}$

\section{Statistical Analysis}

The statistical analysis of this study was largely descriptive. Descriptive statistics such as mean and percentage were used to characterize the data. Univariate analysis was performed to understand which factors were associated with better outcome. Factors that were studied included duration of the deficit prior to treatment, complete palsy, use of coils, follow-up time, Raymond classification (complete occlusion vs partial occlusion), and aneurysm size. Statistically significant difference in outcomes based on treatment parameters was determined by Fisher's exact test. A p value of $<0.05$ was determined to be statistically significant. Odds ratios were computed when possible with their corresponding 95\% confidence intervals. Statistical analysis was performed using JMP version 10.0.0 (SAS Institute).

\section{Results}

Forty-five patients met inclusion criteria for the study, representing 45 treated aneurysms of the proximal intracranial internal carotid artery. The demographic information for the patients is included in Table 1 . There were 42 females (93\%) and 3 males (7\%). The mean age was 64.7 years (range 33-89 years). Of the 45 aneurysms, 26 (57.8\%) were located in the cavernous segment, while 6 $(13.3 \%)$ were in the clinoid segment, and 13 (28.9\%) were in the ophthalmic segment. The average aneurysm size was $18.6 \mathrm{~mm}$ (range $4-35 \mathrm{~mm}$ ). There were 19 aneurysms larger than $20 \mathrm{~mm}, 19$ aneurysms between 10 and $20 \mathrm{~mm}$, and 7 aneurysms smaller than $10 \mathrm{~mm}$. The average number of flow diverters placed per patient was 1.2. Thirty-eight patients had available information regarding duration of cranial neuropathy prior to treatment. Eleven (28.9\%) were treated within 1 month of symptom onset, while 27 (71.1\%) were treated after having symptoms for 1 month.

TABLE 1. Patient demographics

\begin{tabular}{cc}
\hline \multicolumn{1}{c}{ Variable } & Value $^{*}$ \\
\hline No. of patients & 45 \\
\hline Sex & $3(6.67)$ \\
\hline Male & $42(93.33)$ \\
\hline Female & \\
\hline Age in yrs & 64.7 \\
\hline Mean & $33-89$ \\
\hline Range & \\
\hline Cranial neuropathy & $10(22.2)$ \\
\hline II & $16(35.6)$ \\
\hline III & $11(24.4)$ \\
\hline VI & $1(2.2)$ \\
\hline III \& IV & $4(8.9)$ \\
\hline III \& VI & $1(2.2)$ \\
\hline III, IV, \& VI & $2(4.4)$ \\
\hline II, III, IV, \& VI & \\
\hline Aneurysm location & $26(57.8)$ \\
\hline Cavernous segment & $6(13.3)$ \\
\hline Paraclinoid segment & $13(28.9)$ \\
\hline Ophthalmic segment & $12(26.7)$ \\
\hline Comorbidities & $2(4.4)$ \\
\hline Tobacco use &
\end{tabular}

* Values are number of patients (\%) unless otherwise noted. 
TABLE 2. Treatment and clinical demographics

\begin{tabular}{lc}
\hline \multicolumn{1}{c}{ Variable } & Value $^{*}$ \\
\hline Follow-up in mos & 8.4 \\
\hline Mean & $0.1-21.5$ \\
\hline Range & $26(65)$ \\
\hline Raymond class (last follow-up; $n=40)$ & $9(22.5)$ \\
\hline I & $5(12.5)$ \\
\hline II & \\
\hline Raymond class (12 mos; $n=13)$ & $11(84.6)$ \\
\hline I & $2(15.4)$ \\
\hline II & 0 \\
\hline III & \\
\hline Total & $8(17.8)$ \\
\hline Ischemic stroke & $3(6.7)$ \\
\hline Hemorrhagic stroke & $2(4.4)$ \\
\hline GI bleed & $1(2.2)$ \\
\hline New CN deficit & $1(2.2)$ \\
\hline MI & $1(2.2)$ \\
\hline 30-day major stroke or death & $1(2.2)$ \\
\hline
\end{tabular}

$\mathrm{Gl}=$ gastrointestinal; $\mathrm{MI}=$ myocardial infarction .

* Values are number of patients (\%) unless otherwise noted.

The treatment information is summarized in Table 2. The average follow-up was 8.4 months (range 0.1-21.5 months). Forty patients had available follow-up imaging. Radiographically, 26 aneurysms (65\%) were completely occluded, 9 (22.5\%) had a neck residual, and $5(12.5 \%)$ had some residual dome filling at last follow-up. Thirteen patients had 12-month follow-up imaging, with 11 (84.6\%) showing complete occlusion and the remaining 2 (15.4\%) showing a neck remnant. The 30-day morbidity was $17.8 \%$, including 3 ischemic strokes, 2 hemorrhagic strokes, 1 gastrointestinal bleed, 1 myocardial infarction, and 1 new-onset cranial neuropathy. There was 1 ischemic stroke with lasting morbidity, making the 30-day rate of major stroke or death $2.2 \%$.
At last follow-up, the overall rate of cranial neuropathy improvement for all patients was $66.7 \%$ (30/45). Cranial nerve deficits resolved in 19 patients (42.2\%), improved in $11(24.4 \%)$, were unchanged in $14(31.1 \%)$, and worsened in $1(2.2 \%)$. The length of follow-up varied for each patient. Over time, the rate of cranial neuropathy improvement was $33.3 \%(15 / 45), 68.8 \%(22 / 32)$, and $81.0 \%(17 / 21)$ at less than 6,6, and 12 months, respectively. At less than 6 months, $15.6 \%$ (7/45) had worsening of their cranial neuropathy. Between 6 and 12 months, the number decreased to $3.1 \%(1 / 32)$ and $4.8 \%(1 / 21)$, respectively. These data are summarized as a chart in Fig. 1. At 12 months, there were 5 patients with isolated CN II deficits and 14 patients with CN III, IV, or VI (or some combination) deficits. At last follow-up, $60 \%$ of patients with CN II deficits had improved, whereas $85.7 \%$ of those with CN III, IV, or VI deficits had improved. These results, shown over time, are summarized in Fig. 2.

Thirty-eight patients had a known duration of symptoms prior to treatment. At last follow-up, 100\% (11/11) of patients who were treated within 1 month of symptom onset experienced improvement, while $44.4 \%$ (12/27) of those treated after 1 month of symptom onset experienced improvement ( $p=0.002$, Fisher's exact test). Thirty-seven patients had information on the status of their deficit (either partial or complete) on initial workup. At last followup, $70.4 \%$ (19/27) of those with partial deficits improved compared with $30 \%(3 / 10)$ of those with complete deficits ( $\mathrm{p}=0.056$, OR 5.54 [95\% CI 1.14-27.03]). In 40 patients with available follow-up imaging, we analyzed whether aneurysm occlusion resulted in improved recovery of cranial neuropathy. If the aneurysm was completely occluded, there was a trend toward better clinical outcome $(\mathrm{p}=0.12$, RR 1.44 [95\% CI 0.84-2.48]). Forty-four patients had information on the use of coils in addition to flow diversion for treatment of their aneurysm. At last follow-up, $66.7 \%$ $(24 / 36)$ versus $62.5 \%(5 / 8)$ of patients improved with no coils or with coils, respectively $(\mathrm{p}=1.0$, OR $1.2[95 \%$ CI $0.24-5.89])$. With regard to aneurysm size, if an aneurysm was smaller than $20 \mathrm{~mm}, 61.5 \%$ of patients $(16 / 26) \mathrm{im}-$ proved, whereas if the aneurysm was larger than $20 \mathrm{~mm}$ versus $73.7 \%(14 / 19)$ improved ( $p=0.53$, OR 0.57 [95\% CI $0.16-2.08])$. Patients were stratified based on age younger

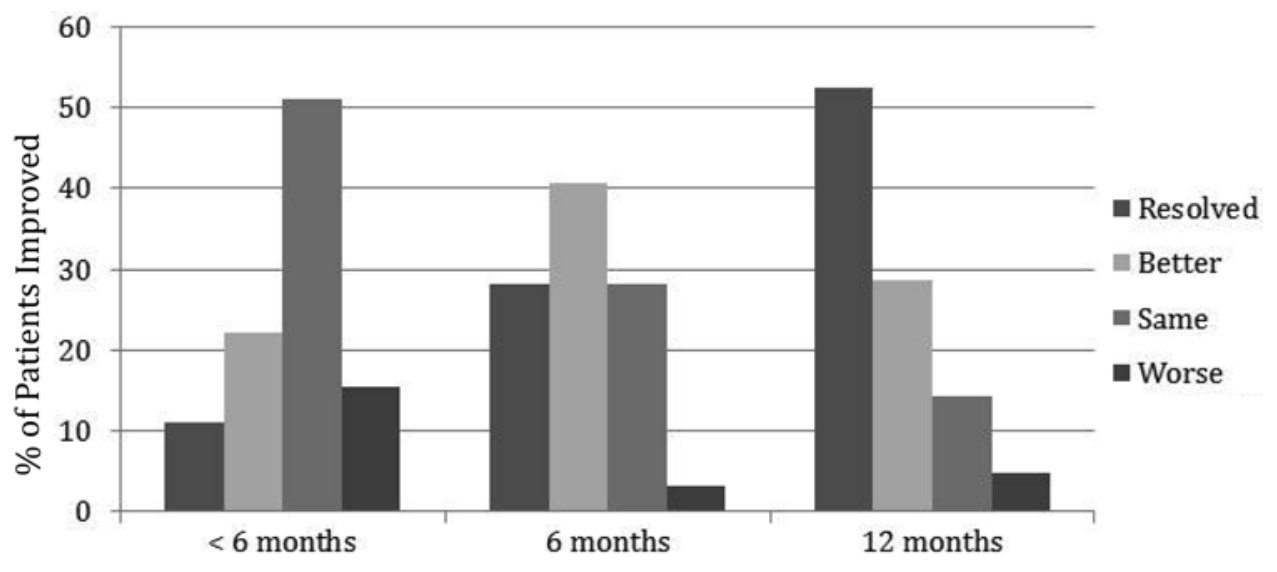

FIG. 1. Cranial neuropathy outcome by follow-up time. 


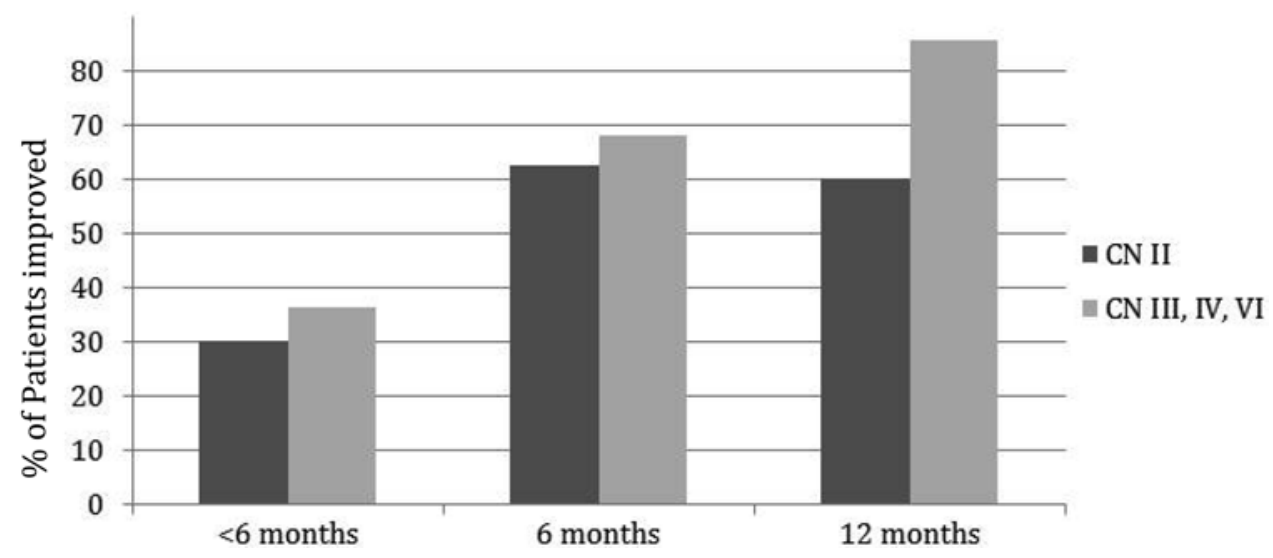

FIG. 2. Comparison of CN II deficit versus CN III, IV, and VI deficit improvement over time.

than 60 years. Those patients in the younger cohort improved $50 \%$ of the time $(8 / 16)$, and those in the older cohort improved $75.9 \%$ of the time $(22 / 29)(p=0.1$, OR 0.32 [95\% CI 0.09-1.16]). These findings are summarized in Table 3.

\section{Discussion}

Our study demonstrates a comparable rate of cranial neuropathy improvement when using flow diversion compared with rates reported in the literature for both microsurgical and endovascular techniques. The bulk of available data involve CNs II and III. A literature search for series of 5 or more patients reporting on resolution of $\mathrm{CNs}$ II and III after surgical and endovascular intervention of cerebral aneurysm was performed. Tables 4 and 5 summarize the literature for CN II and III deficit outcomes, respectively. The improvement rates for $\mathrm{CN}$ II deficits range between $50 \%$ and $100 \%$ (mean $68.6 \%$ ) for microsurgery and between $37.5 \%$ and $60 \%$ (mean $46.2 \%$ ) for coiling. Our series found an improvement rate of $60 \%$ at 12 months for those patients with CN II neuropathy, placing flow diversion slightly behind microsurgery and ahead of coil embolization. The improvement rates for CN III deficits range between $77 \%$ and $100 \%$ (mean $93.6 \%$ ) for

TABLE 3. Secondary analysis

\begin{tabular}{llcc}
\hline \multicolumn{1}{c}{ Factor } & $\%$ Improved & p Value & OR $(95 \% \mathrm{Cl})$ \\
\hline $\begin{array}{l}\text { Treated w/in } 1 \mathrm{mo} \text { of } \\
\text { symptoms }\end{array}$ & $100(11 / 11)$ & 0.002 & $\mathrm{NA}$ \\
\hline $\begin{array}{l}\text { Treated after } 1 \mathrm{mo} \text { of } \\
\text { symptoms }\end{array}$ & $44.4(12 / 27)$ & & \\
\hline Partial deficit & $70.4(19 / 27)$ & 0.056 & $5.54(1.14-27.03)$ \\
\hline Complete deficit & $30(3 / 10)$ & & \\
\hline No coils used & $66.7(24 / 36)$ & 1.0 & $1.2(0.24-5.89)$ \\
\hline Coils used & $62.5(5 / 8)$ & & \\
\hline Aneurysm $<20 \mathrm{~mm}$ & $61.5(16 / 26)$ & 0.53 & $0.57(0.16-2.08)$ \\
\hline Aneurysm $\geq 20 \mathrm{~mm}$ & $73.6(14 / 19)$ & & \\
\hline Age $<60$ yrs & $50(8 / 16)$ & 0.1 & $0.32(0.09-1.16)$ \\
\hline Age $\geq 60$ yrs & $75.9(22 / 29)$ & & \\
\hline
\end{tabular}

microsurgery and between $80 \%$ and $100 \%$ (mean 92.2\%) for coil embolization. In the present series, we found an $85 \%$ improvement rate for deficits CNs III, IV, and VI at 12 months, placing flow diversion slightly behind both microsurgery and coil embolization.

As indicated in Tables 4 and 5, the rates of cranial neuropathy recovery after coiling or surgical clipping of cerebral aneurysms vary widely in published literature. There are a few retrospective studies that analyze predictors of improvement aside from method of treatment. Most of these studies deal with cranial neuropathy due to posterior communicating artery aneurysms. Factors considered are age, duration of symptoms prior to treatment, cranial neuropathy associated with subarachnoid hemorrhage, and cardiovascular risk factors (tobacco use, obesity, dyslipidemia, hypertension, and diabetes). Stiebel-Kalish et al. ${ }^{31}$ reported on 11 patients treated with coiling and noted that age and microvascular risk factors were observed more often in those cases with residual cranial nerve palsy. Ahn et al. ${ }^{1}$ reported on 10 patients who were treated with coiling and 7 patients who underwent microsurgical clipping. In the coiling group, older age, presence of diabetes, complete third nerve palsy at presentation, and delayed treatment were associated with poor prognosis in recovery, whereas in the clipping group, only older age was related to decreased cranial nerve recovery. On the other hand, Kassis et al. ${ }^{18}$ reported outcomes for 20 patients, noting that early management (within 7 days of cranial nerve palsy onset) and clinical presentation with subarachnoid hemorrhage influenced recovery, but cardiovascular risk had no effect. Recently, Chalouhi et al. ${ }^{3}$ observed recovery of nearly $90 \%$ of CN III deficits after endovascular treatment in 37 patients, and partial deficit at presentation was the only statistically significant predictor of complete recovery. Due to the design of previously published studies, it is unclear whether there was an association of recovery prognosis with factors other than the method of treatment, but time to treatment and $\mathrm{CN}$ deficit at presentation are consistently reported.

In the present study, we tested 4 parameters in our secondary analysis: time from onset of neuropathy to treatment, presence of coils, aneurysm size, partial or complete cranial neuropathy, and age. The only factor that reached 
TABLE 4. Literature review for improvement of oculomotor nerve palsies after surgical clipping and coil embolization

\begin{tabular}{lrrc}
\hline \multicolumn{1}{c}{ Authors \& Year } & No. of Patients & No. Improved & $\%$ \\
\hline Surgical clipping & & & \\
\hline Khan et al., 2013 & 8 & 8 & 100 \\
\hline Park et al., 2011 & 13 & 13 & 100 \\
\hline Javalkar et al., 2010 & 26 & 20 & 76.9 \\
\hline Nam et al., 2010 & 8 & 7 & 87.5 \\
\hline Chen et al., 2006 & 7 & 7 & 100 \\
\hline Ahn et al., 2006 & 7 & 7 & 100 \\
\hline Dimopoulos et al., 2005 & 5 & 5 & 100 \\
\hline Fujiwara et al., 1989 & 26 & 22 & 84.6 \\
\hline Mean & & & 93.6 \\
\hline Coil embolization & & & \\
\hline Khan et al., 2013 & 9 & 8 & 88.9 \\
\hline Ko \& Kim, 2011 & 10 & 8 & 80 \\
\hline Nam et al., 2010 & 6 & 5 & 83.3 \\
\hline Kassis et al., 2010 & 20 & 19 & 95 \\
\hline Hanse et al., 2008 & 21 & 19 & 90.5 \\
\hline Chen et al., 2006 & 6 & 6 & 100 \\
\hline Ahn et al., 2006 & 10 & 10 & 100 \\
\hline Stiebel-Kalish et al., 2003 & 11 & 11 & 100 \\
\hline Mean & & & 92.2 \\
\hline & & &
\end{tabular}

statistical significance was time from onset of neuropathy to treatment ( $<1$ month); all 11 patients had improvement in their deficit. Presence of partial versus complete neuropathy at presentation nearly reached statistical significance ( $\mathrm{p}=0.56$, OR 5.54), which is consistent with prior literature, indicating that the degree of deficit has prognostic value regardless of treatment technique. ${ }^{1,3}$ Interestingly, the absence or presence of coils had almost no effect on the improvement rate $(p=1$, OR 1.2$)$, which supports the theory in coiling literature that the cranial neuropathy depends less on mass effect than it does on the pulsatility of the aneurysm sac.

It is important to note that in $15 \%$ of our patients, cranial neuropathy worsened in the short term after placement of a flow diverter. This number decreased to $4.8 \%$ (representing 1 patient) by 12 months. This is important to note for the counseling of patients if flow diversion is to be used.

This study is limited by its retrospective nature as well as the relatively small sample size. Data were extracted from multiple institutions and therefore depend on each institution's records. Formal neuroophthalmological testing was not available for many patients. Another confounding factor in our study is that we examined all recovery of function of all cranial nerves related to visual function (CNs II, III, IV, and VI). CNs III, IV, and VI were grouped together because of their similar function. It is possible that some of these nerves are more likely to improve than others.

The average follow-up time was 8.4 months. In a disease that clearly improves with time, it would be helpful to have longer follow-up times.
TABLE 5. Literature review for improvement of ophthalmic nerve palsies after surgical clipping and coil embolization

\begin{tabular}{lrrc}
\hline \multicolumn{1}{c}{ Authors \& Year } & No. of Patients & No. Improved & $\%$ \\
\hline Surgical clipping & & & \\
\hline Mattingly et al. 2013 & 14 & 11 & 78.6 \\
\hline Dehdashti et al., 2012 & 12 & 9 & 75 \\
\hline Schuss et al., 2011 & 12 & 9 & 75 \\
\hline Park et al., 2009 & 10 & 8 & 80 \\
\hline de Oliveira et al., 2009 & 14 & 14 & 100 \\
\hline Nonaka et al., 2007 & 7 & 3 & 42.9 \\
\hline Hoh et al., 2001 & 12 & 8 & 66.7 \\
\hline Date et al., 1998 & 6 & 3 & 50 \\
\hline Day, 1990 & 23 & 17 & 73.9 \\
\hline Norwood et al., 1986 & 8 & 5 & 62.5 \\
\hline Ferguson \& Drake, 1981 & 14 & 7 & 50 \\
\hline Mean & & & 68.6 \\
\hline Coil embolization & & & \\
\hline Drazin et al., 2013 & 15 & 8 & 53.3 \\
\hline Schuss et al., 2011 & 8 & 3 & 37.5 \\
\hline Heran et al., 2007 & 15 & 7 & 46.7 \\
\hline Malisch et al., 1998 & 6 & 2 & 33.3 \\
\hline Halbach et al., 1994 & 5 & 3 & 60 \\
\hline Mean & & & 46.2 \\
\hline
\end{tabular}

\section{Conclusions}

Cranial neuropathy caused by cerebral aneurysm responds similarly when the aneurysm is treated with PED in comparison with open surgery and coil embolization. Lower morbidity and higher occlusion rates obtained with the PED may suggest it as treatment of choice for some of these lesions. Time to treatment is an important consideration regardless of treatment modality. A prospective study with formal pre- and posttreatment ophthalmological examinations is warranted to verify these findings.

\section{Acknowledgments}

Dr. Siddiqui receives research grants from the NIH and the University at Buffalo (not related to the current work).

\section{References}

1. Ahn JY, Han IB, Yoon PH, Kim SH, Kim NK, Kim S, et al: Clipping vs coiling of posterior communicating artery aneurysms with third nerve palsy. Neurology 66:121-123, 2006

2. Becske T, Kallmes DF, Saatci I, McDougall CG, Szikora I, Lanzino G, et al: Pipeline for uncoilable or failed aneurysms: results from a multicenter clinical trial. Radiology 267:858868,2013

3. Chalouhi N, Theofanis T, Jabbour P, Dumont AS, Gonzalez LF, Starke RM, et al: Endovascular treatment of posterior communicating artery aneurysms with oculomotor nerve palsy: clinical outcomes and predictors of nerve recovery. AJNR Am J Neuroradiol 34:828-832, 2013

4. Chen PR, Amin-Hanjani S, Albuquerque FC, McDougall C, Zabramski JM, Spetzler RF: Outcome of oculomotor nerve palsy from posterior communicating artery aneurysms: 
comparison of clipping and coiling. Neurosurgery 58:10401046, 2006

5. Date I, Asari S, Ohmoto T: Cerebral aneurysms causing visual symptoms: their features and surgical outcome. Clin Neurol Neurosurg 100:259-267, 1998

6. Day AL: Aneurysms of the ophthalmic segment. A clinical and anatomical analysis. J Neurosurg 72:677-691, 1990

7. de Oliveira JG, Borba LA, Rassi-Neto A, de Moura SM, Sanchez-Júnior SL, Rassi MS, et al: Intracranial aneurysms presenting with mass effect over the anterior optic pathways: neurosurgical management and outcomes. Neurosurg Focus 26(5):E3, 2009

8. Dehdashti AR, Le Roux A, Bacigaluppi S, Wallace MC: Long-term visual outcome and aneurysm obliteration rate for very large and giant ophthalmic segment aneurysms: assessment of surgical treatment. Acta Neurochir (Wien) 154:43-52, 2012

9. Dimopoulos VG, Fountas KN, Feltes CH, Robinson JS, Grigorian AA: Literature review regarding the methodology of assessing third nerve paresis associated with non-ruptured posterior communicating artery aneurysms. Neurosurg Rev 28:256-260, 2005

10. Drazin D, Choulakian A, Nuño M, Gandhi R, Edgell RC, Alexander MJ: Improvement in visual symptomatology after endovascular treatment of cavernous carotid aneurysms: a multicenter study. J Vasc Interv Neurol 6:15-21, 2013

11. Ferguson GG, Drake CG: Carotid-ophthalmic aneurysms: visual abnormalities in 32 patients and the results of treatment. Surg Neurol 16:1-8, 1981

12. Fujiwara S, Fujii K, Nishio S, Matsushima T, Fukui M: Oculomotor nerve palsy in patients with cerebral aneurysms. Neurosurg Rev 12:123-132, 1989

13. Halbach VV, Higashida RT, Dowd CF, Barnwell SL, Fraser KW, Smith TP, et al: The efficacy of endosaccular aneurysm occlusion in alleviating neurological deficits produced by mass effect. J Neurosurg 80:659-666, 1994

14. Hanse MC, Gerrits MC, van Rooij WJ, Houben MP, Nijssen PC, Sluzewski M: Recovery of posterior communicating artery aneurysm-induced oculomotor palsy after coiling. AJNR Am J Neuroradiol 29:988-990, 2008

15. Heran NS, Song JK, Kupersmith MJ, Niimi Y, Namba K, Langer DJ, et al: Large ophthalmic segment aneurysms with anterior optic pathway compression: assessment of anatomical and visual outcomes after endosaccular coil therapy. J Neurosurg 106:968-975, 2007

16. Hoh BL, Carter BS, Budzik RF, Putman CM, Ogilvy CS: Results after surgical and endovascular treatment of paraclinoid aneurysms by a combined neurovascular team. Neurosurgery 48:78-90, 2001

17. Javalkar V, Cardenas R, Nanda A: Recovery of third nerve palsy following surgical clipping of posterior communicating artery aneurysms. World Neurosurg 73:353-356, 2010

18. Kassis SZ, Jouanneau E, Tahon FB, Salkine F, Perrin G, Turjman F: Recovery of third nerve palsy after endovascular treatment of posterior communicating artery aneurysms. World Neurosurg 73:11-16, e2, 2010

19. Khan SA, Agrawal A, Hailey CE, Smith TP, Gokhale S, Alexander MJ, et al: Effect of surgical clipping versus endovascular coiling on recovery from oculomotor nerve palsy in patients with posterior communicating artery aneurysms: A retrospective comparative study and meta-analysis. Asian J Neurosurg 8:117-124, 2013

20. Ko JH, Kim YJ: Oculomotor nerve palsy caused by posterior communicating artery aneurysm: evaluation of symptoms after endovascular treatment. Interv Neuroradiol 17:415-419, 2011

21. Malisch TW, Guglielmi G, Viñuela F, Duckwiler G, Gobin YP, Martin NA, et al: Unruptured aneurysms presenting with mass effect symptoms: response to endosaccular treatment with Guglielmi detachable coils. Part I. Symptoms of cranial nerve dysfunction. J Neurosurg 89:956-961, 1998

22. Mattingly T, Kole MK, Nicolle D, Boulton M, Pelz D, Lownie SP: Visual outcomes for surgical treatment of large and giant carotid ophthalmic segment aneurysms: a case series utilizing retrograde suction decompression (the "Dallas technique"). J Neurosurg 118:937-946, 2013

23. Nam KH, Choi CH, Lee JI, Ko JG, Lee TH, Lee SW: Unruptured intracranial aneurysms with oculomotor nerve palsy: clinical outcome between surgical clipping and coil embolization. J Korean Neurosurg Soc 48:109-114, 2010

24. Nonaka T, Haraguchi K, Baba T, Koyanagi I, Houkin K: Clinical manifestations and surgical results for paraclinoid cerebral aneurysms presenting with visual symptoms. Surg Neurol 67:612-619, 2007

25. Norwood EG, Kline LB, Chandra-Sekar B, Harsh GR III: Aneurysmal compression of the anterior visual pathways. Neurology 36:1035-1041, 1986

26. Park J, Kang DH, Chun BY: Superciliary keyhole surgery for unruptured posterior communicating artery aneurysms with oculomotor nerve palsy: maximizing symptomatic resolution and minimizing surgical invasiveness. J Neurosurg 115:700-706, 2011

27. Park JH, Park SK, Kim TH, Shin JJ, Shin HS, Hwang YS: Anterior communicating artery aneurysm related to visual symptoms. J Korean Neurosurg Soc 46:232-238, 2009

28. Raymond J, Guilbert F, Weill A, Georganos SA, Juravsky L, Lambert A, et al: Long-term angiographic recurrences after selective endovascular treatment of aneurysms with detachable coils. Stroke 34:1398-1403, 2003

29. Schuss P, Güresir E, Berkefeld J, Seifert V, Vatter H: Influence of surgical or endovascular treatment on visual symptoms caused by intracranial aneurysms: single-center series and systematic review. J Neurosurg 115:694-699, 2011

30. Stiebel-Kalish H, Kalish Y, Bar-On RH, Setton A, Niimi Y, Berenstein A, et al: Presentation, natural history, and management of carotid cavernous aneurysms. Neurosurgery 57:850-857, 2005

31. Stiebel-Kalish H, Maimon S, Amsalem J, Erlich R, Kalish Y, Rappaport HZ: Evolution of oculomotor nerve paresis after endovascular coiling of posterior communicating artery aneurysms: a neuro-ophthalmological perspective. Neurosurgery 53:1268-1274, 2003

\section{Disclosure}

The authors report the following: Dr. Lopes: consultant for Covidien. Dr. Rawk: stock ownership in Blockade Medical. Dr. Ringer: consultant for Covidien, MicroVention, and Stryker. Dr. Arthur: consultant for Covidien, Codman, Stryker, MicroVention, Penumbra, and Sequent. Dr. Hoit: consultant for Covidien. Dr. Snyder: support of non-study-related clinical or research effort from Boston Scientific, Cordis, Endtex, Medtronic, Abbott Vascular, ev3, Toshiba, Micrus, Zimmer, EPI, Guidant, Kerberos and Primus; stock ownership in Boston Scientific, Access Closure, and Niagara Gore Medical; financial interest in Cordis, Endotex, Micrus, and EPI; and consultant for Medtronic, Abbott Vascular, ev3, Toshiba, Micrus, and Zimmer; and Primus. Dr. Siddiqui: stock ownership in Hotspur, Intratech Medical, StimSox, Valor Medical, Blockade Medical, Lazarus Effect, Pulsar Vascular, and Medina Medical; consultant for Codman \& Shurtleff, Inc., Covidien Vascular Therapies, Guidepoint Global Consulting, Penumbra Inc., Stryker, Pulsar Vascular, MicroVention, Lazarus Effect, Blockade Medical, and Reverse Medical; speakers' bureau for Codman \& Shurtleff; advisory board of Codman \& Shurtleff, Covidien Neurovascular, ICAVL, and Medina Medical; honoraria from Abbott Vascular and Codman \& Shurtleff. Dr. Levy: 
ownership in Intratech Medical Ltd. and Blockade Medical LLC; National PI for SWIFT Prime Trials for Covidien and Carotid Training Sessions for Physicians for Abbott; and legal opinion as an expert witness for Renders Medical. Dr. Hopkins: consultant for Boston Scientific, Cordis, Abbott Vascular, Covidien; direct stock ownership in Boston Scientific, Valor Medical, Claret Medica, Inc., Augmenix, Endomation, Silk Road, Ostial, Apama, StimSox, Photolitec, ValnTx, Ellipse, Axria, NextPlain, and MedinaMed; research grant from Toshiba; speakers' bureau for Abbott Vascular and Toshiba; honoraria from Cordis, Memorial HealthCare System, Complete Conf. Management, and Covidien; and board position for Claret Medical. Dr. Mocco: Consultant for Lazarus effect, Reverse, Pulsar, Edge Therapeutics, and Medina; and investor in Blockade Medical and Medina; and advisory board for Codman Neurovascular. Dr. Hanel: consultant for Covidien, Stryker, and Codman; stock ownership in Blockade; and scientific advisory board for Medina.

\section{Author Contributions}

Conception and design: Brown, Hanel. Acquisition of data: Brown, Lopes, Miller, Tawk, Brasiliense, Ringer, Sauvageau, Powers, Arthur, Hoit, Snyder, Siddiqui, Levy, Hopkins, Cuellar, Rodriquez-Mercado, Veznedaroglu, Binning, Mocco, Boulos, Yamamoto, Hanel. Analysis and interpretation of data: Brown, Aguilar-Salinas, Hanel. Drafting the article: Brown. Critically revising the article: Brown, Hanel. Reviewed submitted version of manuscript: Brown, Brasiliense, Hanel. Approved the final version of the manuscript on behalf of all authors: Brown. Statistical analysis: Brown, Aguilar-Salinas. Administrative/technical/ material support: Brasiliense. Study supervision: Hanel.

\section{Correspondence}

Benjamin Brown, Department of Neurosurgery, Mayo Clinic, 4500 San Pablo Rd., Jacksonville, FL 32224. email: brown. benjamin1@mayo.edu. 